\title{
Angle Class III malocclusion with severe anteroposterior discrepancy
}

\author{
Carlos Alexandre Câmara*
}

\begin{abstract}
This case report describes the treatment of a 36-year-old patient who presented a skeletal and dental Class III malocclusion and missing upper canines. The patient was treated with orthosurgical maxillary advancement (Le Fort 1) and occlusal adjustment of the first premolars, which replaced the canines. This case was presented to the Brazilian Board of Orthodontics and Facial Orthopedics (BBO), as representative of Category 4, i.e., malocclusion with severe anteroposterior discrepancy, as part of the requirements for obtaining the BBO Diploma.
\end{abstract}

Keywords: Angle Class III malocclusion. Maxillofacial surgery. Corrective Orthodontics.

\section{HISTORY AND ETIOLOGY}

Caucasian patient aged 36, female, in good health and with average caries experience. No reported history of serious or chronic diseases. The patient reported in her initial consultation that her facial profile was concave since childhood and her upper canines were extracted at an early age. Her main complaint concerned a disharmony of the anterior teeth and dissatisfaction with the functional and aesthetic aspects.

\section{DIAGNOSIS}

A physical examination revealed that the patient had Class III skeletal and dental malocclusion characteristics. Occlusal relationship seemed atypical since the premolars were found to be replacing the canines, which were missing. The first lower left molar was also absent. Thus, the right side molar relationship was in Class I and the relationship between canines in atypical Class III with the premolars replacing the canines. There was an anterior $-4 \mathrm{~mm}$ crossbite and a slight lower arch midline shift ( $1 \mathrm{~mm}$ to the left). The posterior crowns seemed enlarged and showed signs of gingival recession (Figs 1 and 2).

A sagittal view of the patient's face showed that the middle third was retruded in relation to the upper and lower thirds. Maxillary deficiency was evidenced by the near absence of zygomatic projection and infraorbital depression. Moreover, the mandible did not show a long chin-neck line ${ }^{1}$. In frontal view, no significant discrepancies were noted. The relative vertical expansion of the lower third was well evidenced by the disparity between

\footnotetext{
* Specialist in Orthodontics, Rio de Janeiro State University. Brazilian Board of Orthodontics and Dentofacial Orthopedics Diplomate.
} 
the upper lip, lower lip and chin, which were at a ratio of 1:3, when the ideal would be $1: 2 .^{2}$ This disparity gave the impression that half of the lower third looked "heavy", especially for a female face. The maxillary retrusion further contributed to this impression, which was possibly enhanced by the missing upper canines. Smile aesthetics was also affected by the retrusive maxilla due to a low smile line and inadequate upper incisor exposure (Fig 1).
The panoramic radiograph showed horizontal bone loss in both arches (Fig 3).

Assessment of the lateral cephalometric radiograph (Fig. 4) confirmed the Class III skeletal pattern with $\mathrm{ANB}$ equal to $-10^{\circ}\left(\mathrm{SNA}=74^{\circ}\right.$ and $\left.\mathrm{SNB}=84^{\circ}\right)$ and compensatory inclination of the incisors $\left(1-\mathrm{NA}=30^{\circ}, 1-\mathrm{NB}=19^{\circ}\right.$ and $\mathrm{IMPA}=$ $84^{\circ}$ ). These and other measurements can be seen in Table 1.
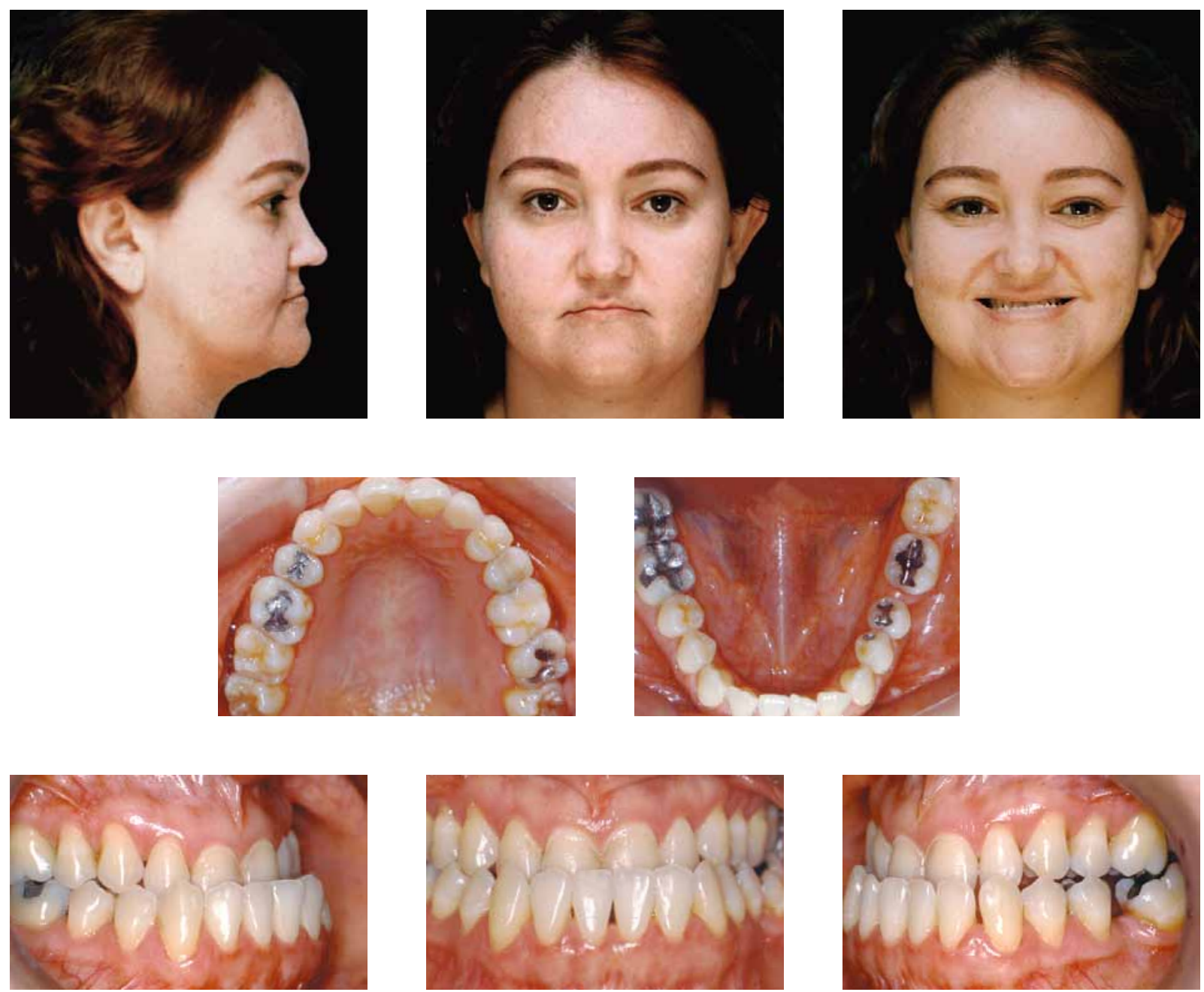

FIGURE 1 - Initial facial and intraoral photographs. 

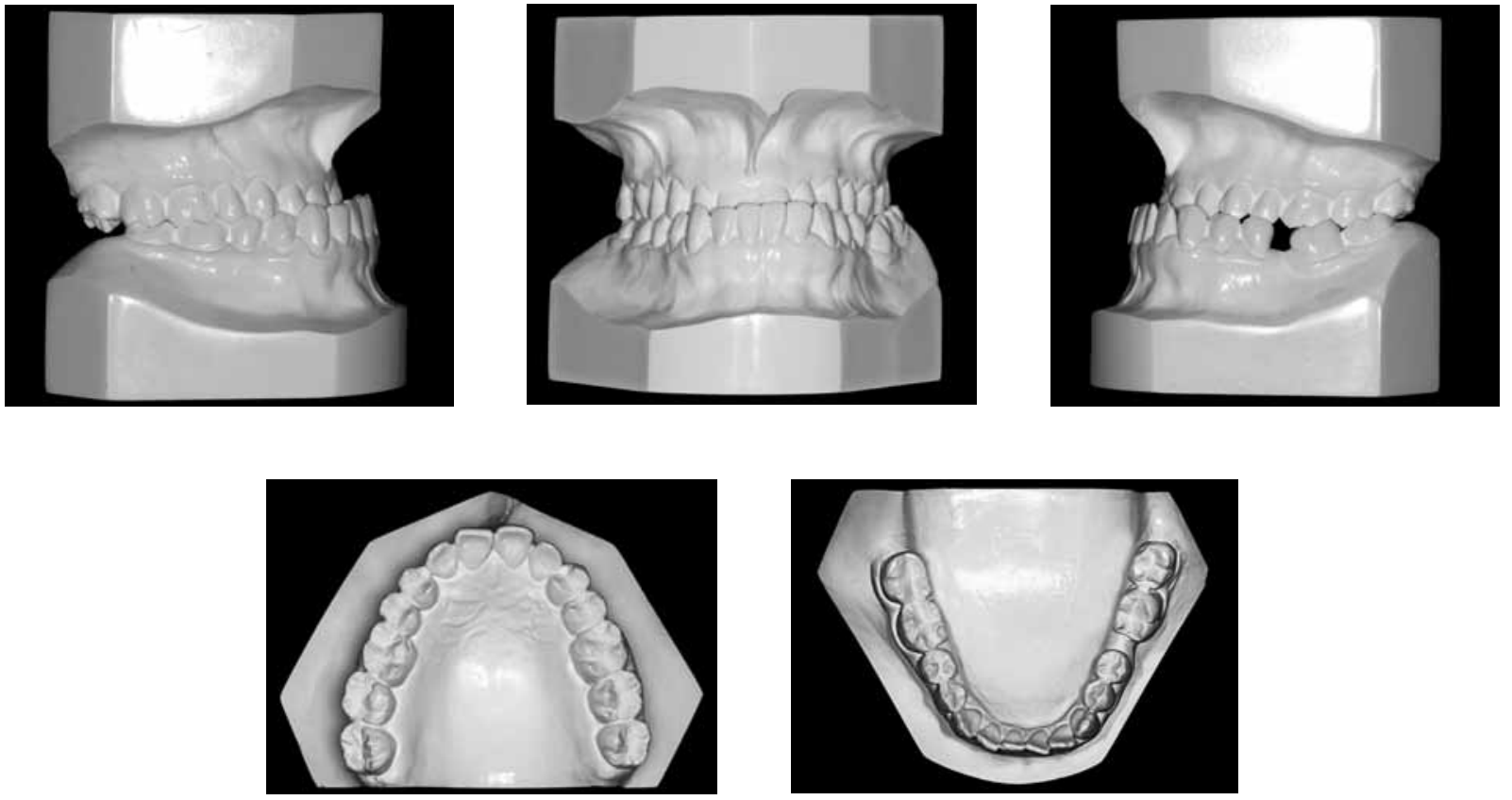

FIGURE 2 - Initial casts

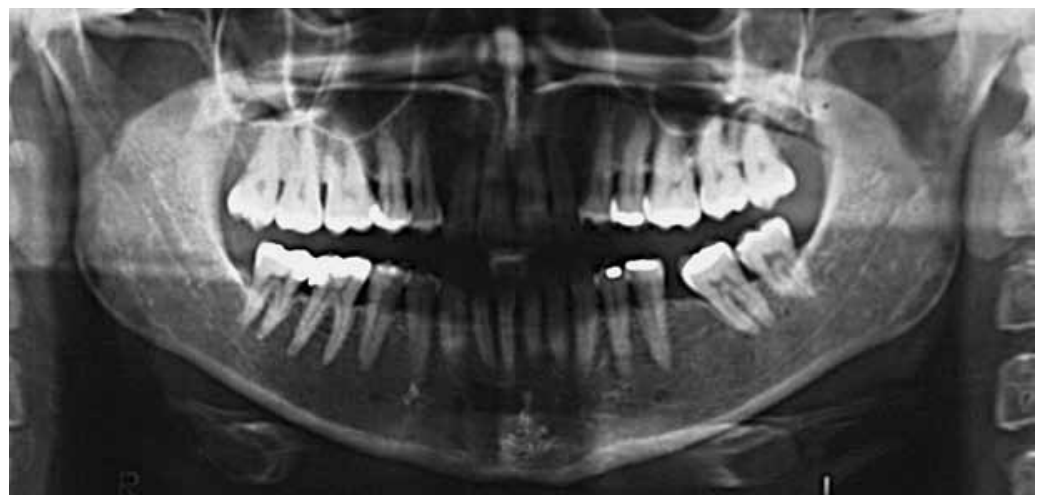

FIGURE 3 - Initial panoramic radiograph.
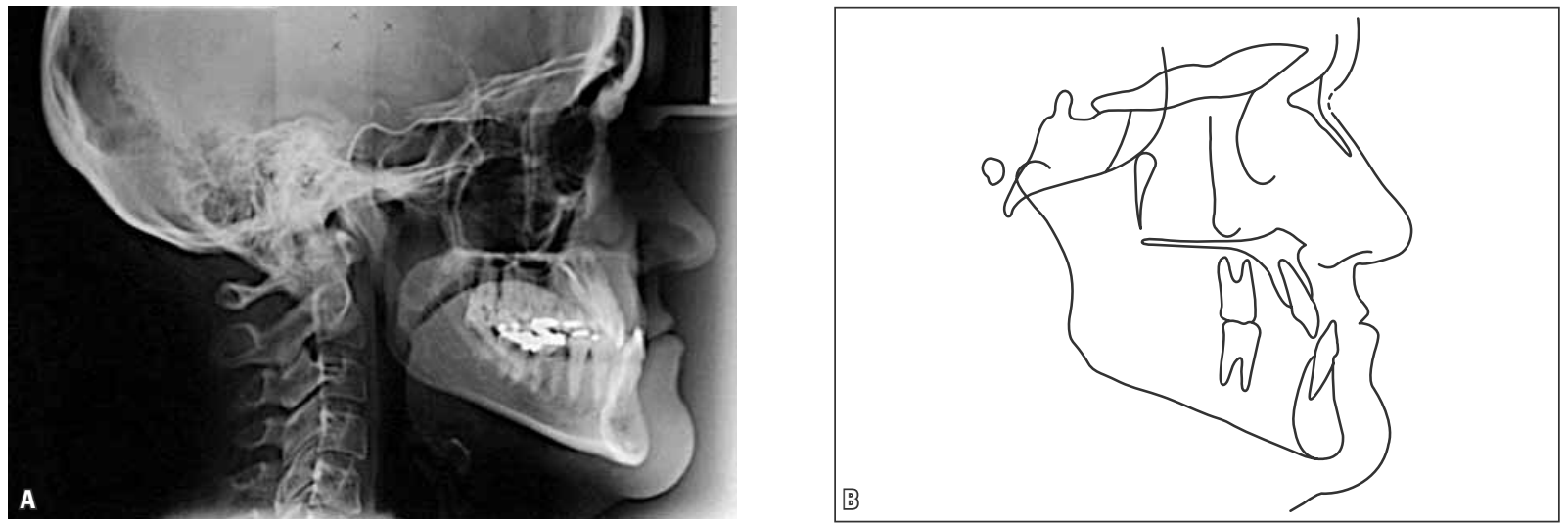

FIGURE 4 - Initial lateral cephalometric radiograph (A) and cephalometric tracing (B). 


\section{TREATMENT GOALS}

Treatment goals were based on the maxillary deficiency that led to the midface retrusion. The anterior crossbite resulting from the maxillary retrusion and missing maxillary canines required correction by means of surgical maxillary advancement. The establishment of normal occlusion-according to Andrews's six keys to optimal occlusion-was achieved through maxillary advancement and occlusal adjustment of the premolars that replaced the canines. Presurgical orthodontic decompensation was accomplished by aligning and leveling the upper and lower arches. For the lower arch it was decided that the space left by the missing tooth (36) would be closed during the orthodontic mechanics of decompensation. The surgical goal focused on maxillary advancement since the maxilla was retruded in relation to the lower third and the mandible did not show a significant disparity, as attested by the normal length of the chin-neck line.

\section{TREATMENT PLAN}

The treatment plan was based on the need for dental decompensation for presurgical preparation. It also consisted in installing the upper and lower fixed appliance (Standard Edgewise system, 0.022 x 0.028-in slot, round 0.012-in, 0.014-in, 0.016-in, 0.018-in, 0.020-in and rectangular 0.019 x 0.025in arch wires). All orthodontic wires were stainless steel, except the first, which was a NiTi. In the final stage of alignment and leveling with round arches the use of Class II elastics was started with the purpose of decompensating the lingual inclination in the lower anterior crowns and preparing for placement of the rectangular $0.019 \times 0.025$-in arch wire. The use of Class II-oriented elastics would also serve to assist in closing the space between teeth 37 and 35, caused by the absence of 36 .

Following the insertion of the rectangular wires, casts were made of the upper and lower arches to analyze a simulation of the postsurgical occlusion. As soon as the occlusion was prepared additional documentation was ordered for evaluation and study prior to surgery. The surgery goal was maxillary advancement (Le Fort I) with rigid fixation using plates and screws. The last phase would involve finishing the case with special attention to first premolar torque setting. Before the removal of the fixed appliance an appointment was scheduled for occlusal adjustment and to refine the occlusal contacts and lateral and anterior guides.

Lower retention consisted of a 0.032 -in braided wire retainer bonded to the lingual surface of the anterior teeth, from canine to canine. In the upper arch a wraparound removable upper plate was used, made with 0.032-in stainless steel wire.

\section{TREATMENT PROGRESS}

The orthodontic appliance was comprised of brackets, which were bonded from premolar to premolar and molar bands, which were placed on the molars (including the third molars). Buccal tubes were bonded to the lower second molars. With the exception of the first 0.012-in orthodontic arch wires, which were $\mathrm{NiTi}$, all others were stainless steel. The use of these arch wires allowed the customization of arch size diagrams and the use of sizes that enabled arch decompensation. In other words, any compensation generated by the initial malocclusion was corrected based on individual features and on the ideal size for the patient's arches. It should be noted that the distance between the canines and lower molars served as a reference for producing upper and lower diagrams. The use of customized contoured arch wires which conformed to such measurements allowed a slow and gradual decompensation. However, the decompensation of the maxillary transverse width caused a decrease in intermolar width, bringing about a stalemate. In fact, the decrease in intermolar width occurred on account of torque correction. Since this was a Class III malocclusion case, even when these teeth are not crossed they do present with lingual root torque compensations. ${ }^{3}$ Thus, after correcting the torque of the posterior teeth a discrepancy 
was found between maxillary and mandibular widths. Whenever the cast models were manipulated to simulate the postsurgical position a lingual crossbite appeared. In fact, maxillary atresia was also expressed in the transverse dimension. Thus, there was a discrepancy between the maxillary and mandibular bone bases which showed up after dental decompensation. The ideal solution to this problem would be maxillary expansion surgery performed either prior to or during advancement surgery, thus segmenting the maxilla. However, the simulation models showed that the crossbite was negligible. This fact, compounded by the disadvantages of a two-step surgery (expansion and advancement), such as discomfort and compromised esthetics, as well as, on the other hand, the possibility of relapse ${ }^{5}$ after a singlestep surgery, led the author to compensate for the transverse discrepancy between the maxilla and mandible by increasing molar buccal root torque,
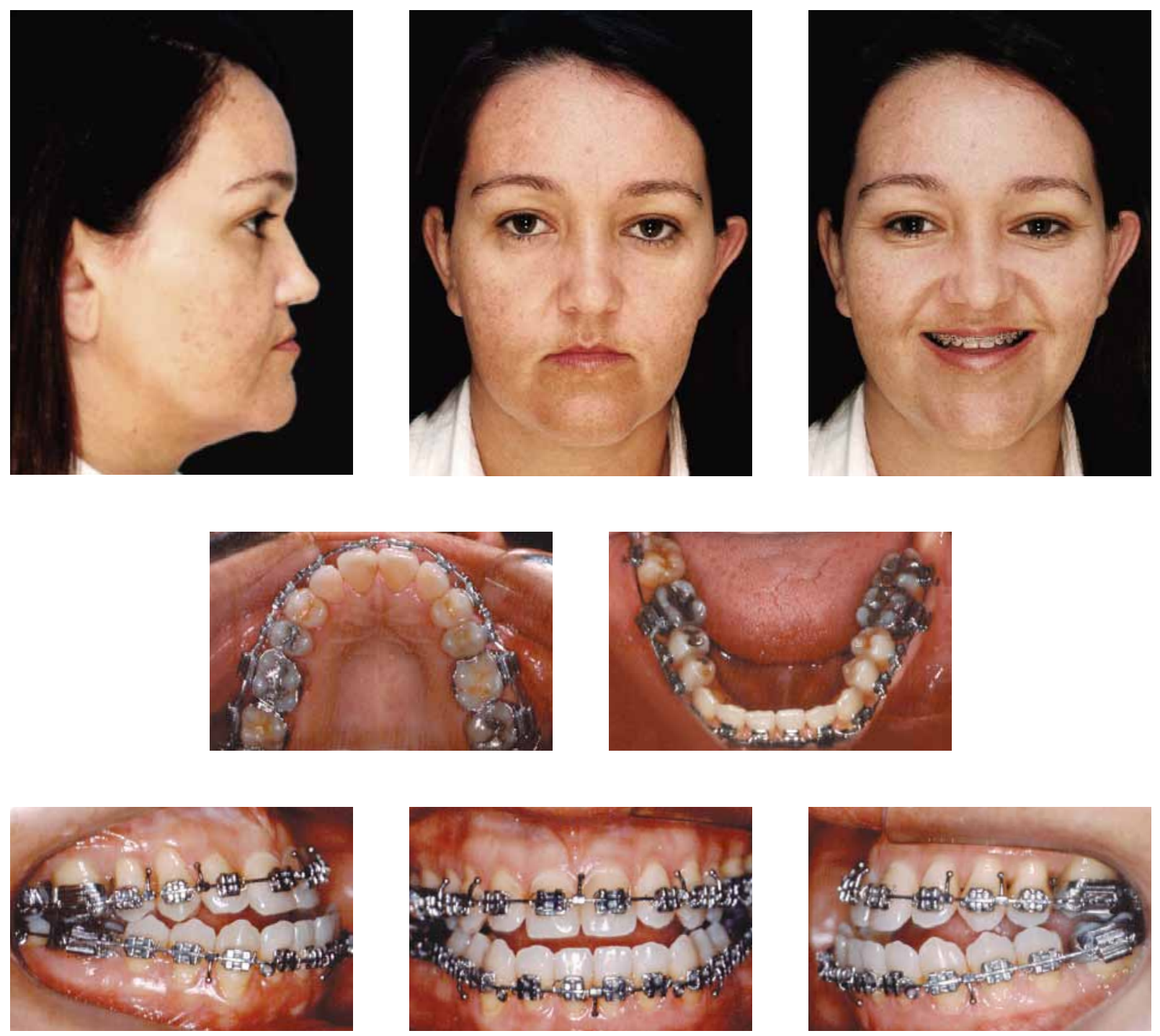

FIGURE 5 - Presurgical facial and intraoral photographs. 
which shortened the intermolar width of these teeth (Table 2). In other words, the proper fit between upper and lower molars in the transverse direction was achieved by dental compensation through molar buccal root torque, which allowed the palatal cusps of the upper molars to occlude with the fossae and marginal ridges of the lower molars. After such compensations additional exams were ordered for surgical planning and the patient was referred for surgery (Figs 5 to 9).

As expected, an $8 \mathrm{~mm}$ maxillary advancement enabled the correction of the anterior crossbite with an atypical occlusion relationship since the upper first premolars had replaced the canines.
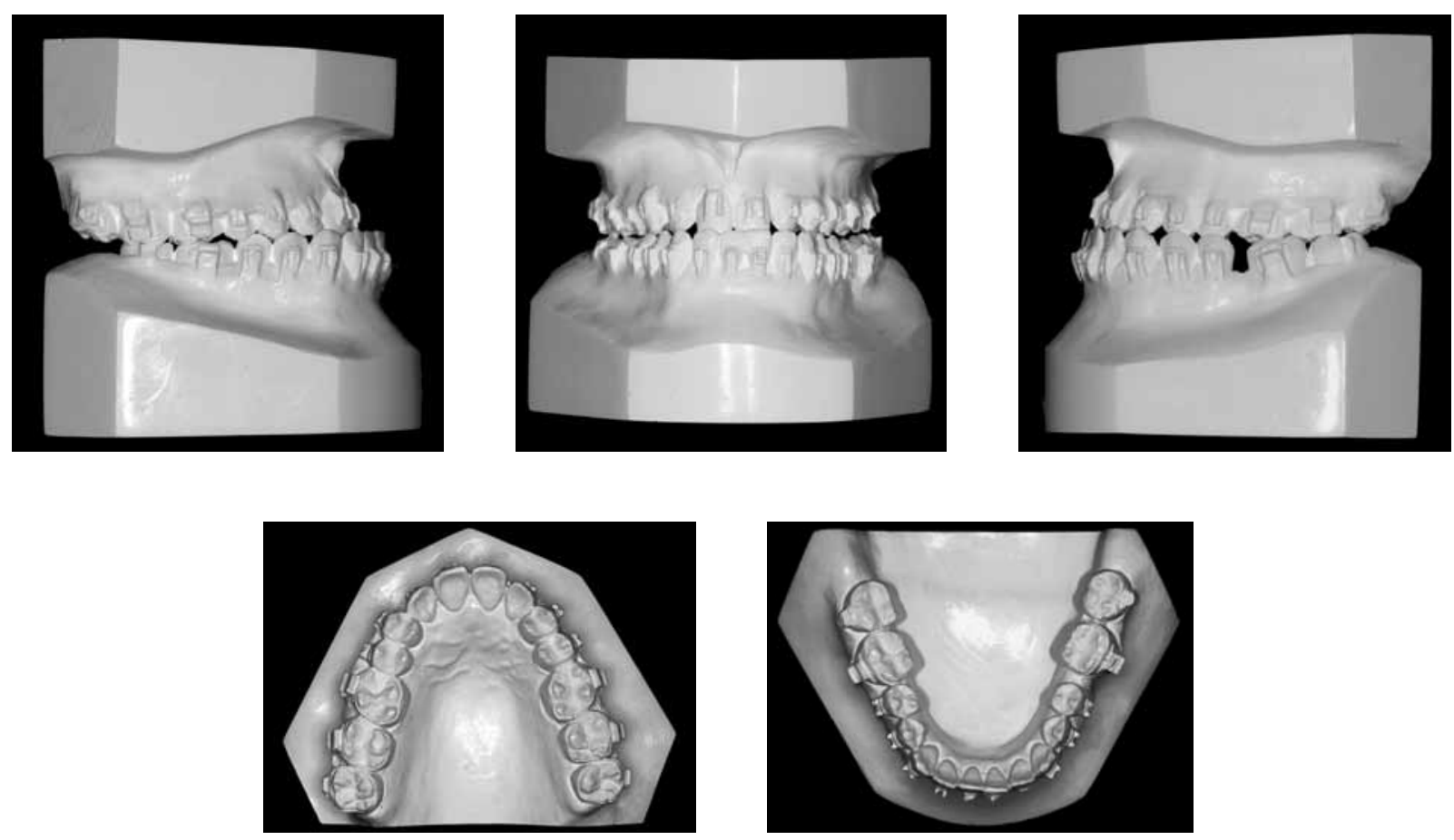

FIGURE 6 - Presurgical cast models.

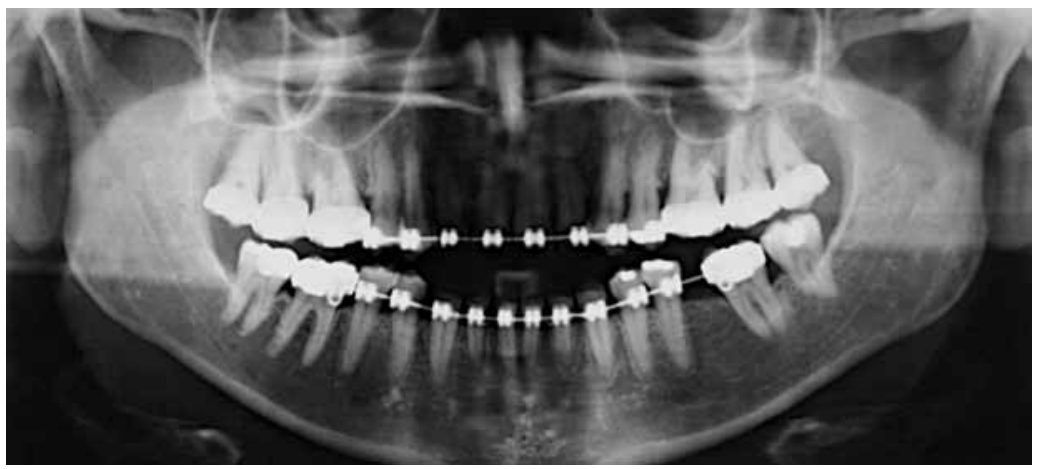

FIGURE 7 - Presurgical panoramic radiograph. 

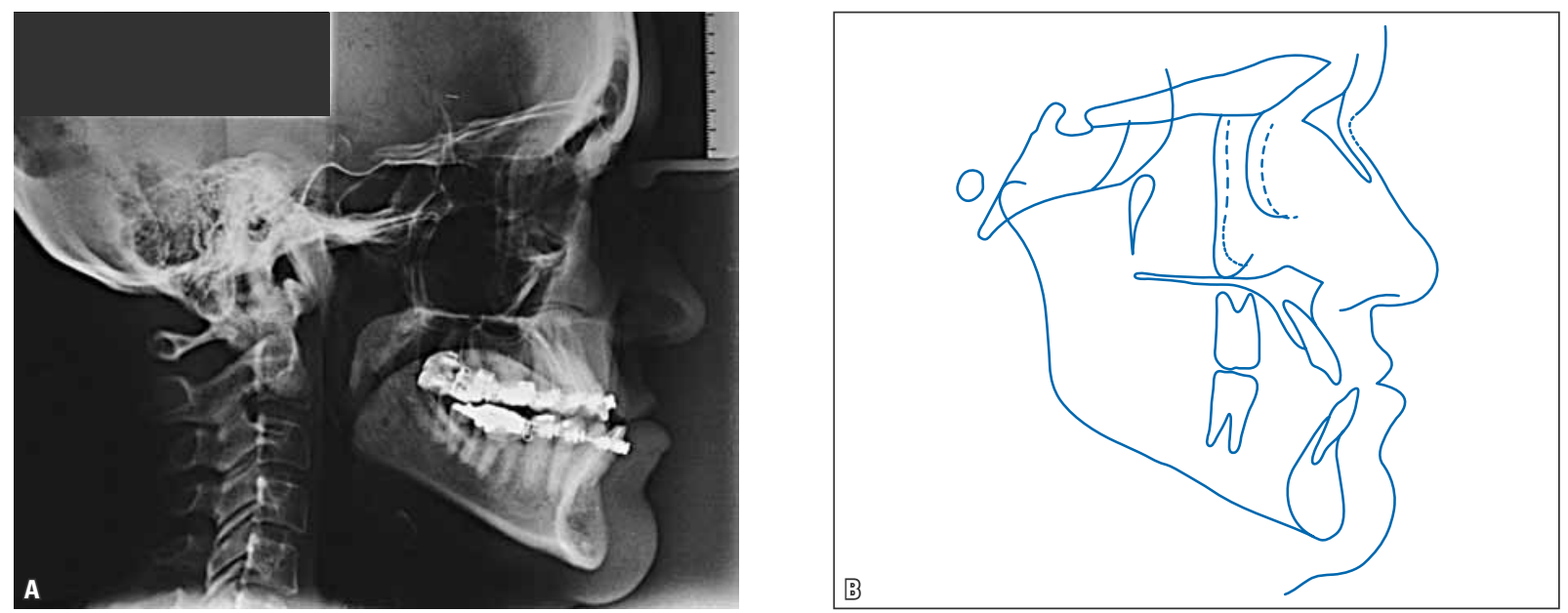

FIGURE 8 - Presurgical lateral cephalometric radiograph (A) and cephalometric tracing (B).
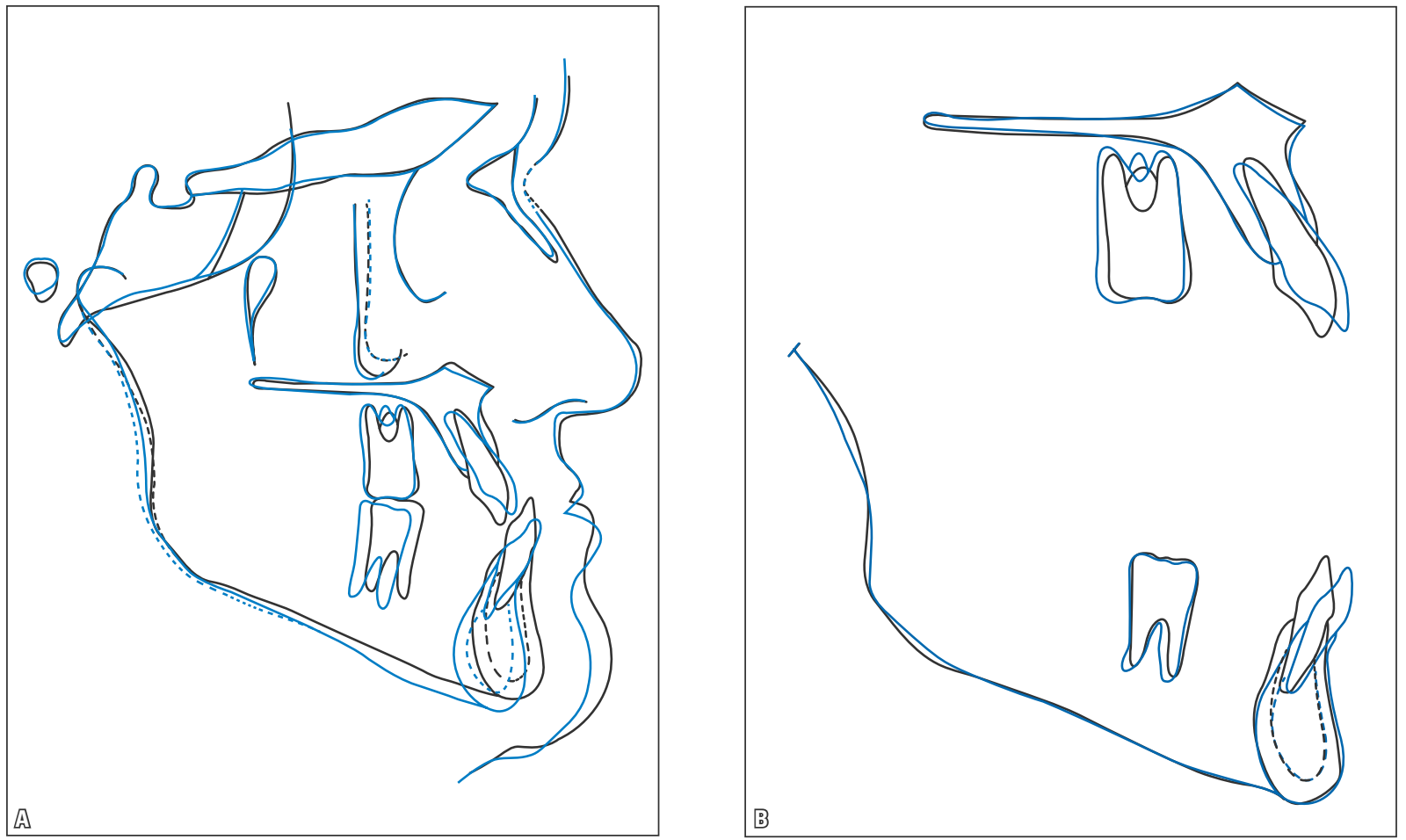

FIGURE 9 - Total (A) and partial (B) superimposition of initial (black) and presurgical (blue) cephalometric tracings. 
In the final stage, after the orthodontic adjustments, occlusal adjustment was performed by wearing down the upper first premolar region so that the occlusal contacts were simultaneous and bilateral, exerting equipotent axial forces with no lateral resultant forces. The lateral guides were obtained through group disocclusion so as to not force or traumatize the premolars, which already presented with gingival recession before treatment. The occlusal adjustments were refined six months after appliance removal. The space left by tooth 36 was closed using orthodontic elastic chains and with the aid of inter maxillary elastics used before surgery (Fig 10).

The planned retainers were used. In the upper arch a removable wraparound appliance and in the lower, 0.032-in braided wire was bonded from canine to canine.
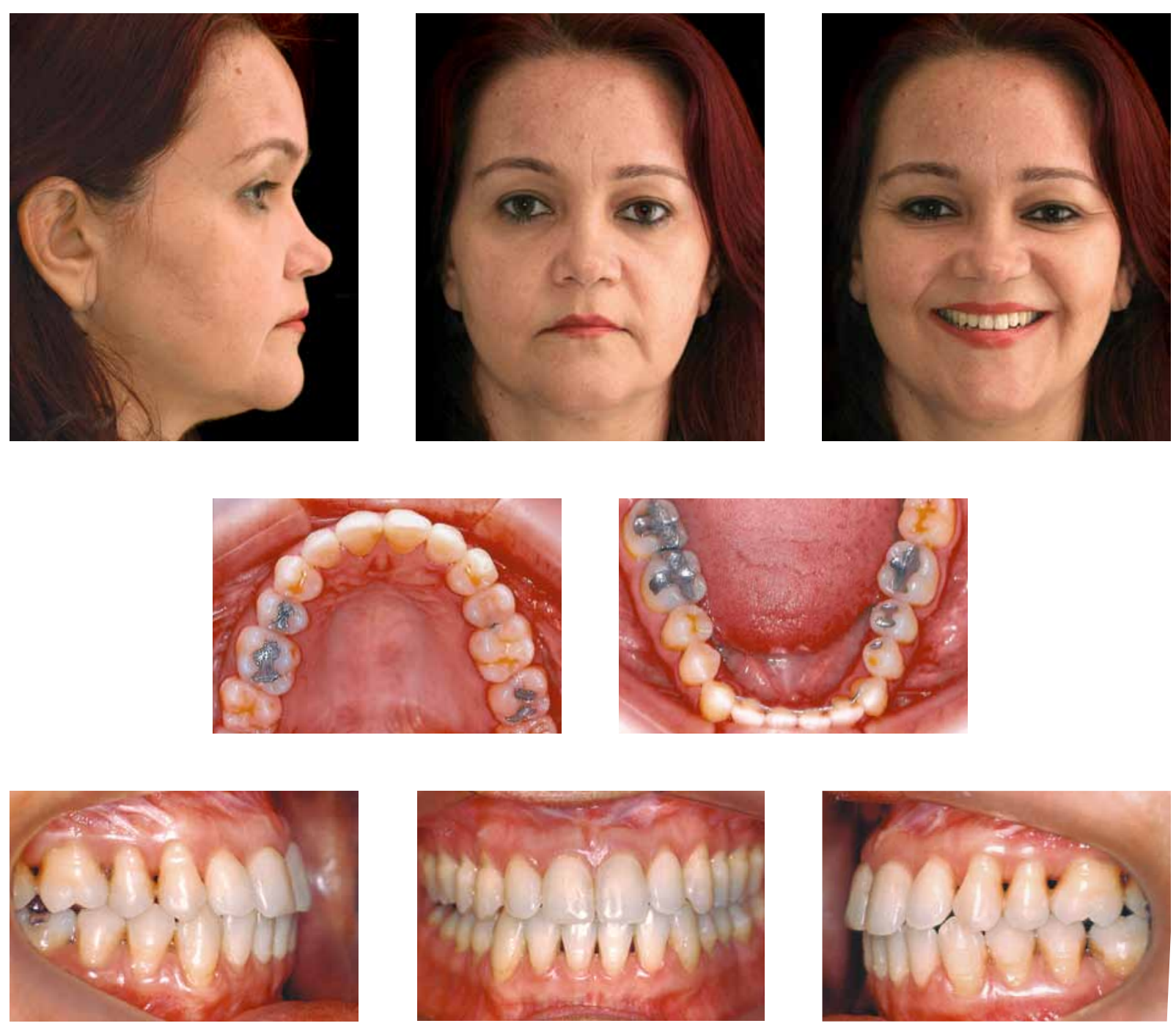

FIGURE 10 - Final facial and intraoral photographs. 


\section{TREATMENT RESULTS}

The $8 \mathrm{~mm}$ surgical maxillary advancement (Le Fort 1) corrected the sagittal discrepancy of the Class III malocclusion with a reduction in ANB from $-10^{\circ}$ to $0^{\circ}$ (Table 1). Incisor decompensation allowed the anterior crossbite to be corrected and correct vertical and horizontal overlaps were achieved. The space of the missing first lower left molar was taken by the second molar, which kept a Class II relationship on both left and right sides due to the absence of canines. The premolars replaced the canines and after the necessary orthodontic adjustments and some wearing down of the occlusal contacts also assumed their function. The maxillary advancement also provided aesthetic enhancement since both the profile and the smile showed significant improvement. The profile became more
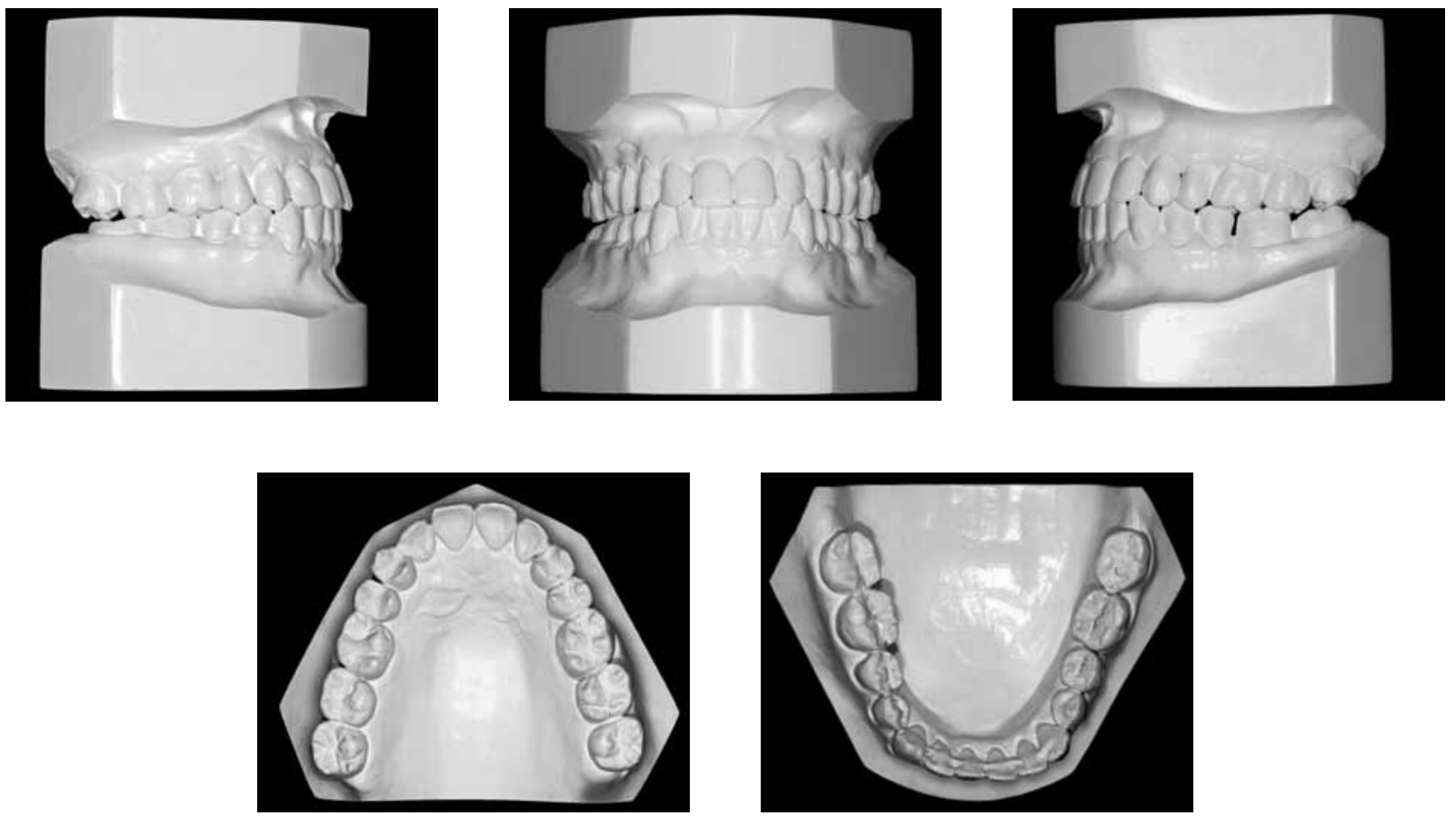

FIGURE 11 - Final cast models.

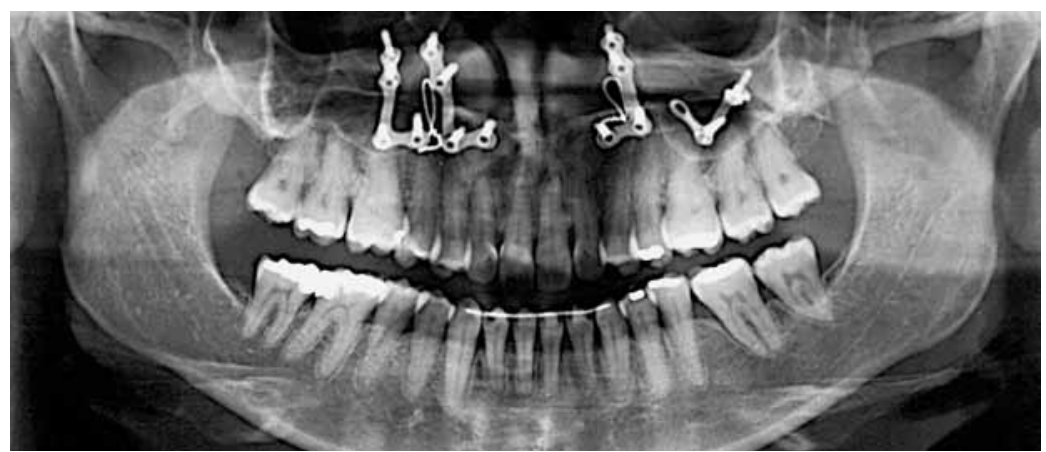

FIGURE 12 - Final panoramic radiograph. 
balanced with well-proportioned facial thirds. The proper positioning and greater exposure of the upper incisors contributed to a balanced smile. ${ }^{4} \mathrm{~A}$ frontal view of the face at rest showed improvement in the proportions of the facial thirds and in the relationship between the upper lip, lower lip and mentum, which was increased to $1: 2$ (Figs 10 to 14 ).
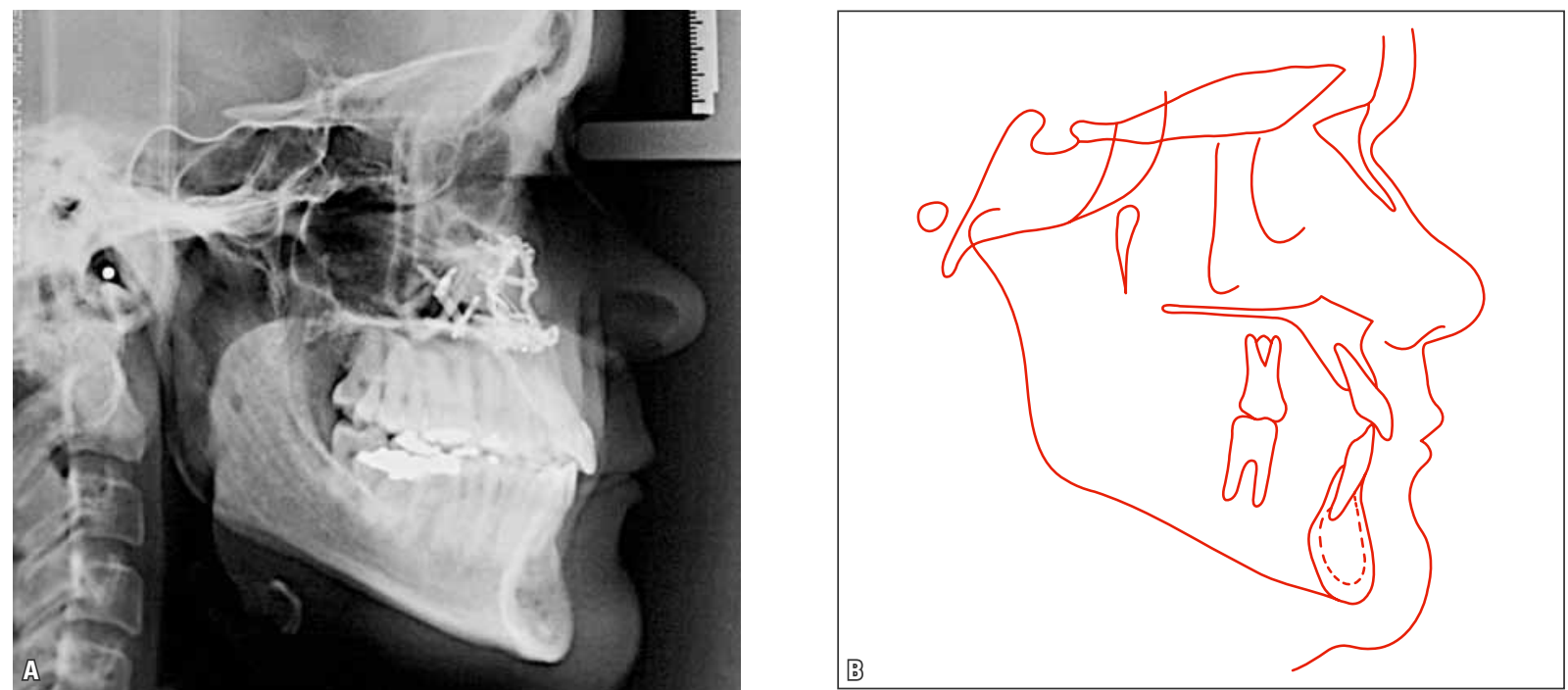

FIGURE 13 - Final lateral cephalometric radiograph (A) and cephalometric tracing (B).
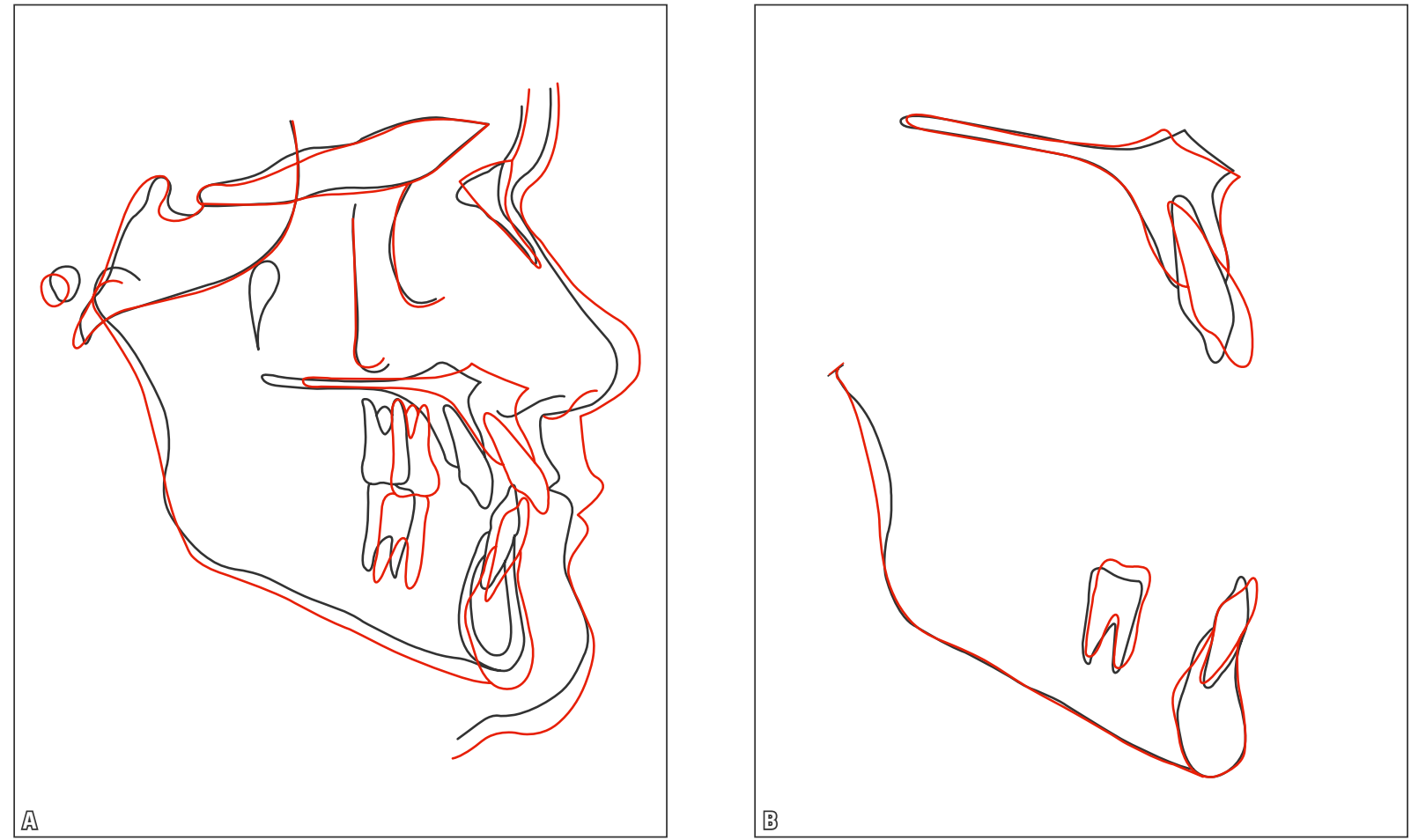

FIGURE 14 - Total (A) and partial (B) superimposition of initial (black) and final (red) cephalometric tracings. 


\section{TREATMENT EVALUATION}

In view of the fact that this was an adult patient with a Class III malocclusion, surgery was always an option. Maxillary advancement was preferred because the midface was retruded in relation to the upper and lower thirds. This retrusion showed that there was a maxillary atresia which, accompanied by an absence of canines, compounded the retrusive effect with a $4 \mathrm{~mm}$ anterior crossbite. Moreover, although there was a discrepancy in position between maxilla and mandible, the mandible was not excessively large. This fact was attested by the normal length of the chin-neck line. In addition, two factors were crucial to the maxillary surgery. Firstly, there was a risk that mandibular setback might interfere with the reduction of oropharynx space, which might lead to the emergence of a respiratory disorder, in particular, Obstructive Sleep Apnea. Secondly, the possibility of relapse is reduced when a single bone is moved. ${ }^{5}$ Four years later, result stability confirmed this expectation (Figs 15 to 19).

The correction of skeletal and dental problems allowed the occlusal, functional and aesthetic goals to be achieved.
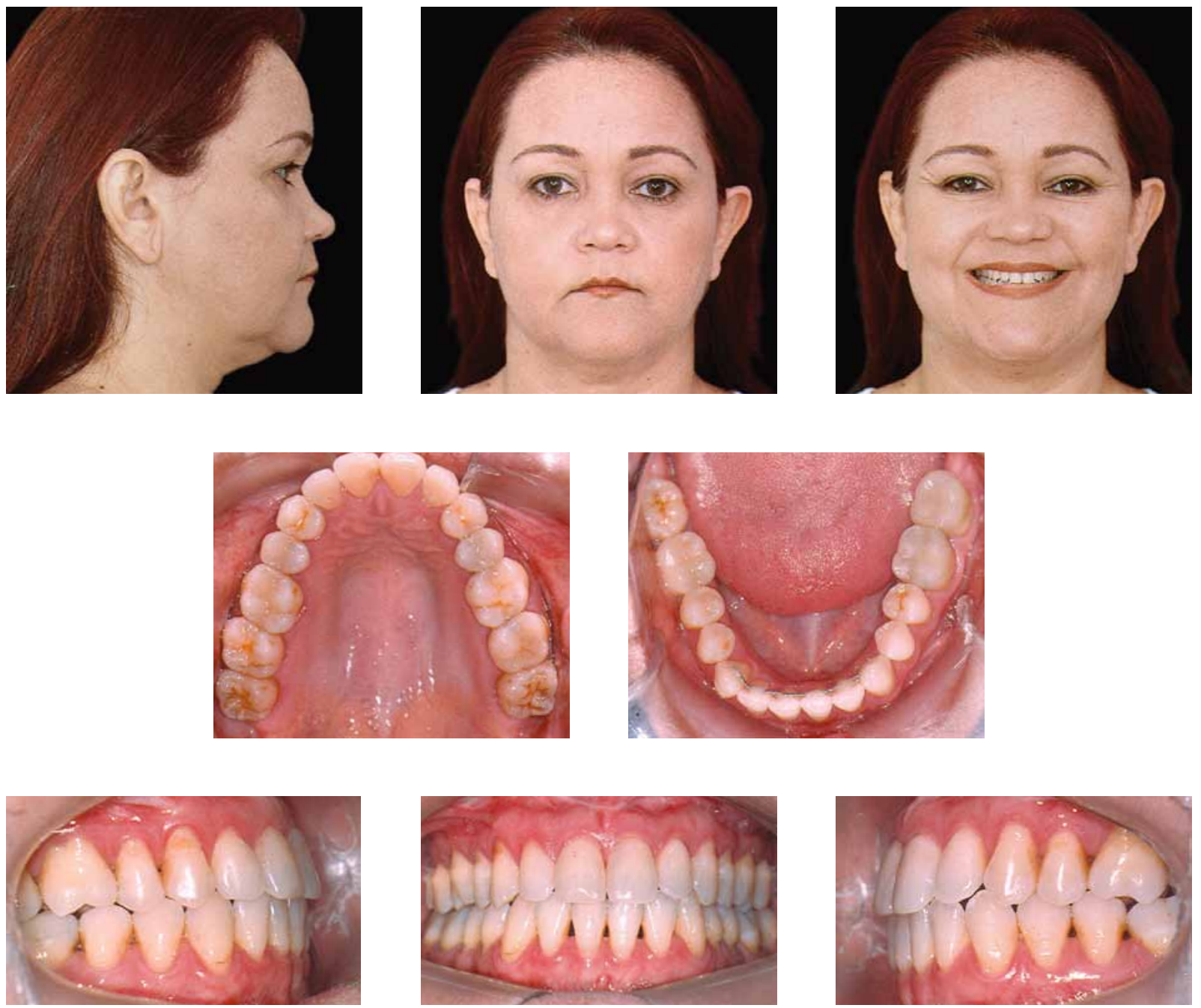

FIGURE 15 - Facial and intraoral control photographs taken four years after treatment completion. 

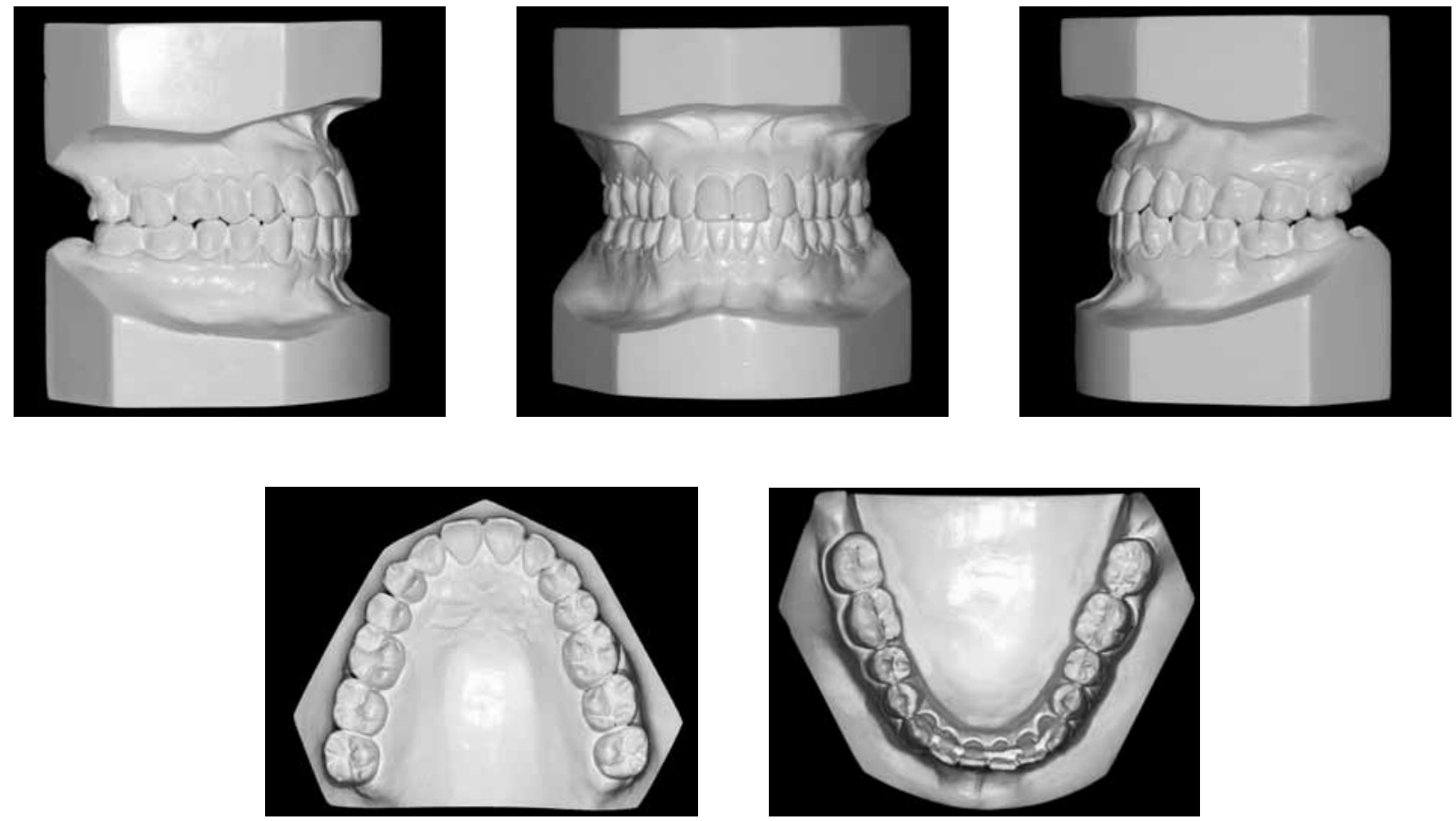

FIGURE 16 - Control casts four years after treatment completion.

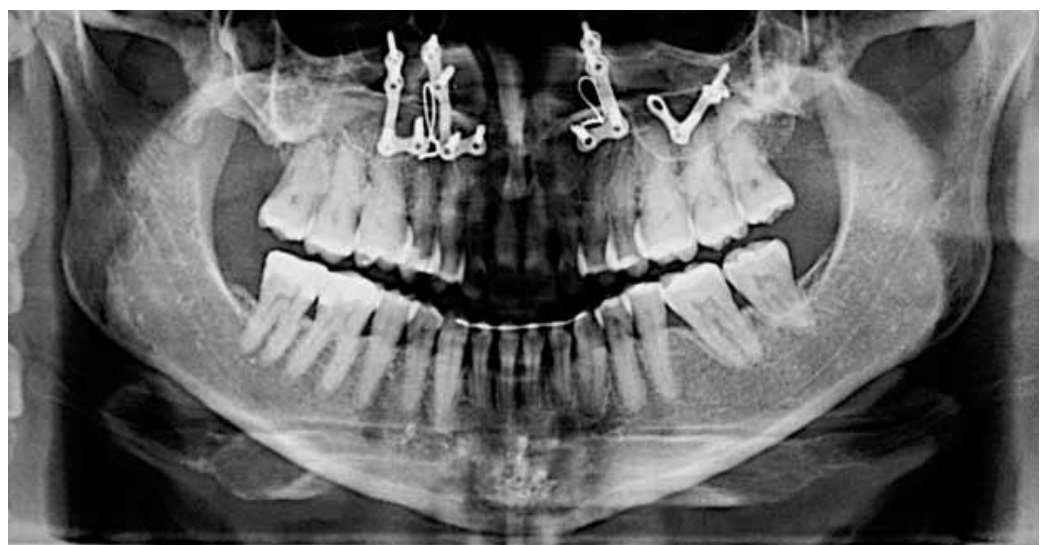

FIGURE 17 - Panoramic radiograph four years after treatment completion. 

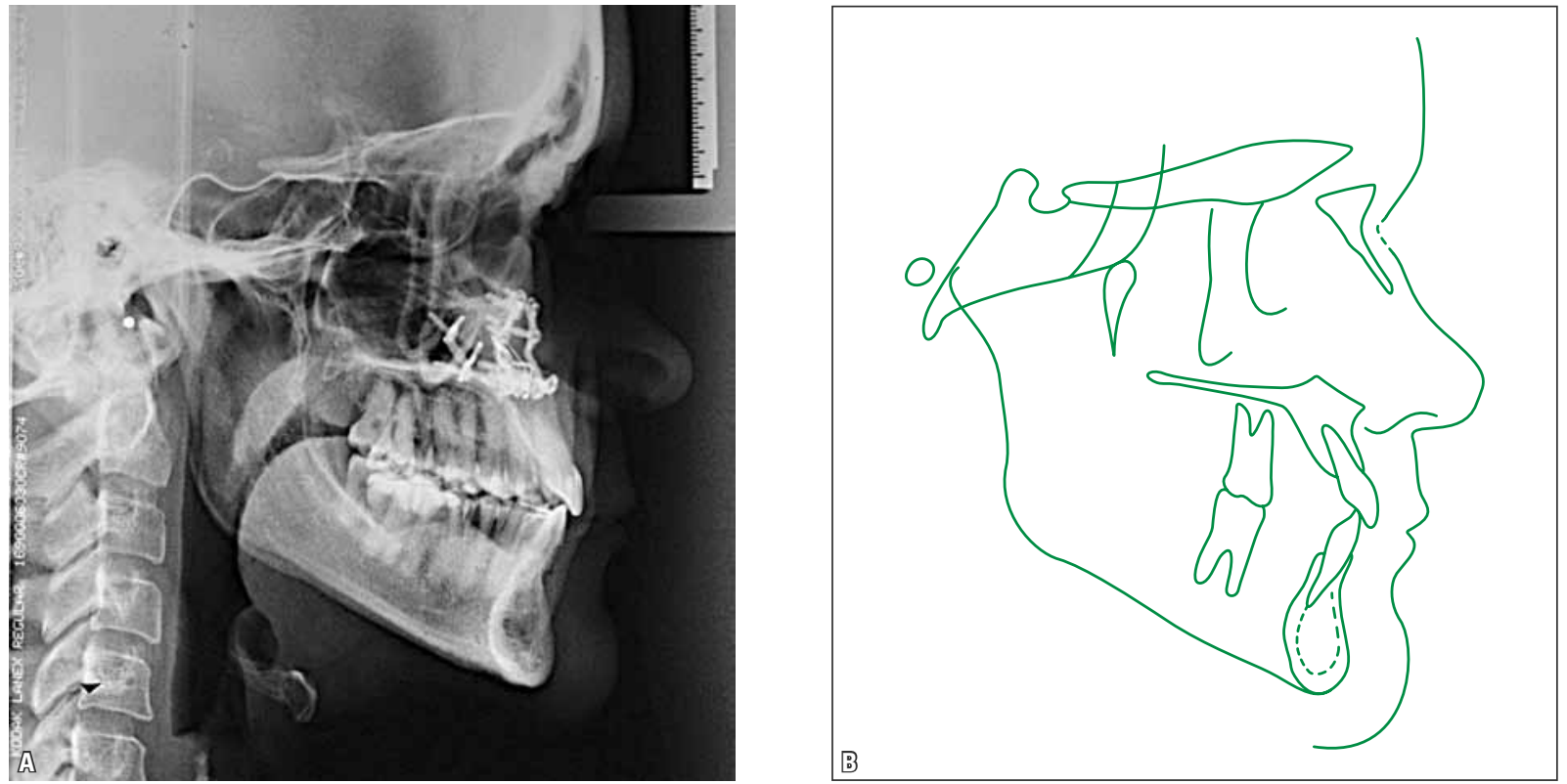

FIGURE 18 - Profile lateral radiograph (A) and cephalometric tracing (B) - four years after treatment completion.
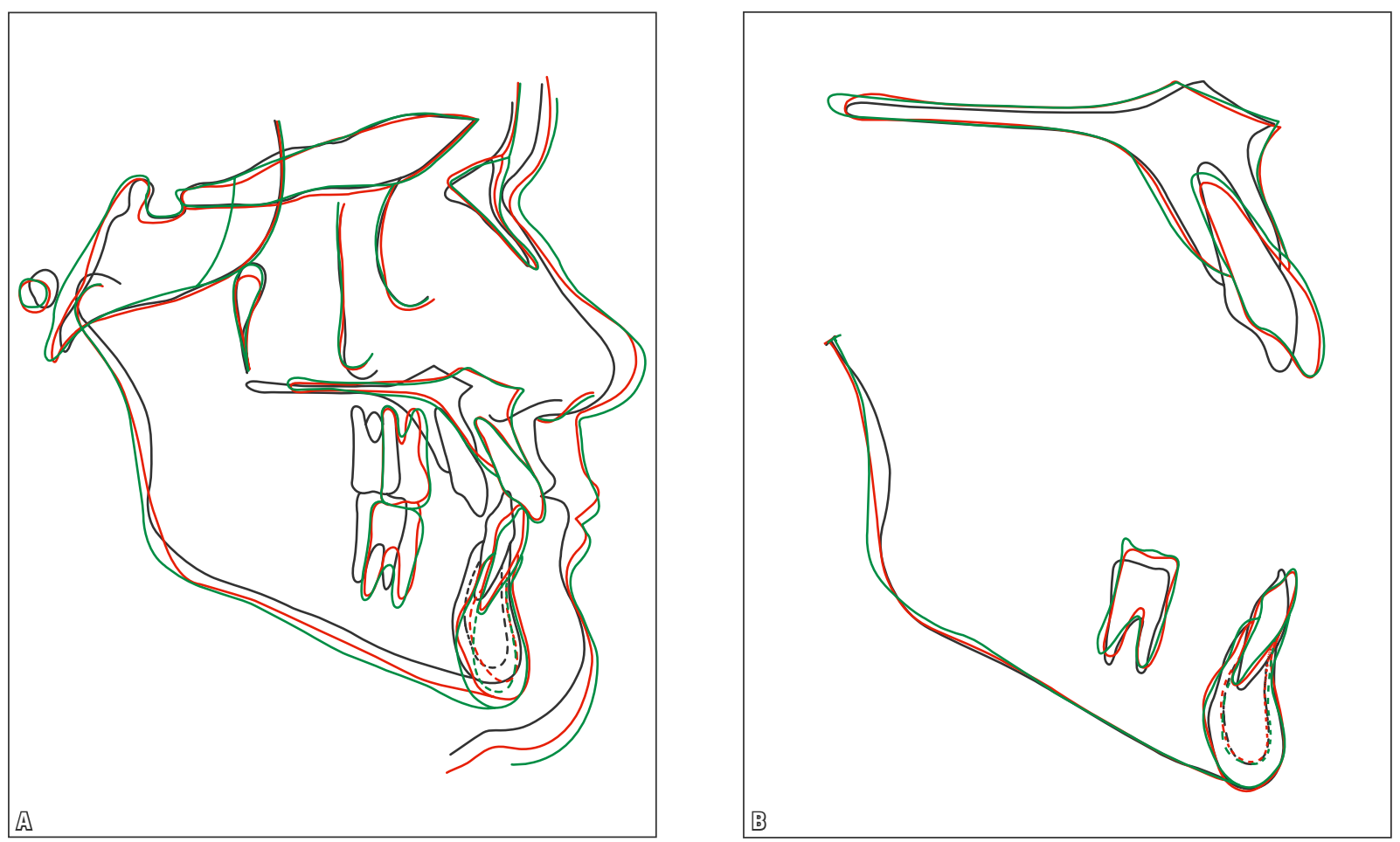

FIGURE 19 - Total (A) and partial (B) superimposition of initial (black), final (red) and control (green) cephalometric tracings four years after treatment completion. 
TABLE 1 - Summary of cephalometric measurements.

\begin{tabular}{|c|c|c|c|c|c|c|c|c|c|}
\hline & \multicolumn{2}{|c|}{ MEASUREMENTS } & NORMAL & A & A1 & $\mathrm{A} 2$ & B & $\begin{array}{c}\text { A - B } \\
\text { DIFFERENCE }\end{array}$ & C \\
\hline \multirow{8}{*}{ 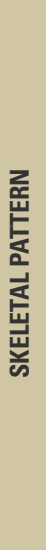 } & SNA & (Steiner) & $82^{\circ}$ & $74^{\circ}$ & $74^{\circ}$ & & $83^{\circ}$ & $9^{\circ}$ & $83^{\circ}$ \\
\hline & SNB & (Steiner) & $80^{\circ}$ & $84^{\circ}$ & $83^{\circ}$ & & $83^{\circ}$ & $2^{\circ}$ & $83^{\circ}$ \\
\hline & ANB & (Steiner) & $2^{\circ}$ & $-10^{\circ}$ & $-11^{\circ}$ & & $0^{\circ}$ & $10^{\circ}$ & $0^{\circ}$ \\
\hline & Convexity Angle & (Downs) & $0^{\circ}$ & $-23^{\circ}$ & $-20^{\circ}$ & & $-4^{0}$ & $19^{\circ}$ & $4^{\circ}$ \\
\hline & Y Axis & (Downs) & $59^{\circ}$ & $50^{\circ}$ & $50^{\circ}$ & & $50^{\circ}$ & $0^{\circ}$ & $50^{\circ}$ \\
\hline & Facial Angle & (Downs) & $87^{\circ}$ & $99^{\circ}$ & $98^{\circ}$ & & $97^{\circ}$ & $2^{\circ}$ & $97^{\circ}$ \\
\hline & SN-GoGn & (Steiner) & $32^{\circ}$ & $29^{\circ}$ & $32^{\circ}$ & & $30^{\circ}$ & $1^{\circ}$ & $30^{\circ}$ \\
\hline & FMA & (Tweed) & $25^{\circ}$ & $16^{\circ}$ & $17^{\circ}$ & & $17^{\circ}$ & $1^{\circ}$ & $17^{\circ}$ \\
\hline \multirow{7}{*}{ 忌 } & IMPA & (Tweed) & $90^{\circ}$ & $84^{\circ}$ & $93^{\circ}$ & & $89^{\circ}$ & $5^{\circ}$ & $88^{\circ}$ \\
\hline & 1 - NA (degrees) & (Steiner) & $22^{\circ}$ & $30^{\circ}$ & $41^{\circ}$ & & $29^{\circ}$ & $1^{\circ}$ & $29^{\circ}$ \\
\hline & 1 - NA (mm) & (Steiner) & 4 & 9 & 11 & & 8 & 1 & 8 \\
\hline & 1 - NB (degrees) & (Steiner) & $25^{\circ}$ & $19^{\circ}$ & $30^{\circ}$ & & $22^{\circ}$ & $3^{\circ}$ & $23^{\circ}$ \\
\hline & $1-\mathrm{NB}(\mathrm{mm})$ & (Steiner) & 4 & 1 & 6 & & 4 & 3 & 4 \\
\hline & 1-1 - Interincisal Angle & (Downs) & $130^{\circ}$ & $140^{\circ}$ & $116^{\circ}$ & & $129^{\circ}$ & $11^{\circ}$ & $128^{\circ}$ \\
\hline & $1-A P_{0}(\mathrm{~mm})$ & (Ricketts) & 1 & 6 & 9 & & 2 & 4 & 3 \\
\hline \multirow{2}{*}{$\begin{array}{l}\text { 픔 } \\
\text { 움 } \\
\text { 움 }\end{array}$} & Upper Lip - S Line & (Steiner) & 0 & -4 & $-3^{\circ}$ & & 0 & 4 & $1^{\circ}$ \\
\hline & Lower Lip - S Line & (Steiner) & 0 & -2 & 2 & & -2 & 0 & 3 \\
\hline
\end{tabular}

TABLE 2 - Upper and lower interpremolar and intermolar widths (in mm).

\begin{tabular}{|c|c|c|c|c|c|}
\hline MEASUREMENTS & A & A1 & B & $\begin{array}{c}\text { A-B } \\
\text { DIFFERENCE }\end{array}$ & C \\
\hline Upper Inter-premolar & 32 & 32 & 32 & 0 & 32 \\
\hline Upper Inter-molar & 45 & 44 & 44 & 1 & 44 \\
\hline Lower Inter-premolar & 25 & 25 & 25 & 0 & 25 \\
\hline Lower Inter-molar & 45 & 40 & 40 & 5 & 41 \\
\hline
\end{tabular}




\section{FINAL CONSIDERATIONS}

Every orthodontic treatment aims to achieve (a) adequate occlusion while ensuring satisfactory and healthy functioning of the stomatognathic system's physiological routine, (b) optimal facial, oral and dental aesthetics and (c) long-term result stability. Adult patients with functional and aesthetic needs raise the level of difficulty in attaining these goals since, deprived of the ability to change provided by bone growth, they require additional, integrated procedures to achieve the desired goals. Angle Class III malocclusion is a classic example of this situation, where orthodontic possibilities are limited and need support from other specialties, particularly surgery. However, the key to a successful treatment lies in understanding and integrating these two specialties in seeking the best alternatives and procedures. In our case, the treatment was carried out through orthodontic preparation and orthognathic surgery. Knowledge of the patient's aesthetic and functional needs as well as her expectations and concerns facilitated the correction of the bone and occlusal discrepancy through maxillary advancement and relocation of upper first premolars to perform the functions of the missing canines. Therefore, although unusual, this case met the requirements of the Brazilian Board of Orthodontics and Facial Orthopedics (BBO), which perceives and assesses treatment results by taking into account the ideal and actual precepts underlying an adequate orthodontic treatment.

\section{ACKNOWLEDGMENTS}

Arthur Farias, for the help in illustration this paper; Sergio Varela, responsible for the surgery in the presented patient; Telma Araujo, for his valuable review. 


\section{REFERENCES}

1. Arnett GW, Bergman RT. Facial Keys to orthodontic diagnosis and treatment planning - Part II. Am J Orthod Dentofacial Orthop. 1993 May;103(5):395-411.

2. Burstone CJ. Lip posture and its significance in treatment planning. Am J Orthod. 1967 Apr; 53(4):262-84.

3. Capelozza Filho L. Diagnóstico em Ortodontia. Maringá: Dental Press; 2004.
4. Câmara CALP. Estética em Ortodontia: Diagramas de Referencias Estéticas Dentárias (DRED) e Faciais (DREF. Rev Dental Press Ortod Ortop Facial. 2006 nov-dez;11(6):130-56.

5. Proffit WR, Turvey TA, Phillips C. Orthognathic surgery: a hierarchy of stability. Int J Adult Orthodon Orthognath Surg. 1996;11(3):191-204.

Submitted: December 2009

Revised and accepted: February 2010

\section{Contact address}

Carlos Alexandre Câmara

Rua Joaquim Fagundes 597, Tirol

CEP: 59.022-500 - Natal / RN, Brazil

E-mail: cac.ortodontia@digi.com.br 